\title{
Sciendo
}

\section{Interpretable Machine-Learning Approach in Estimating FDI Inflow: Visualization of ML Models with LIME and $\mathrm{H} 2 \mathrm{O}$}

\author{
Devesh Singh \\ University of Kaposvár \\ Guba Sandor u. 40 \\ Kaposvár 7400, Hungary \\ Email: Dev.singh.ece@gmail.com
}

\begin{abstract}
In advancement of interpretable machine learning (IML), this research proposes local interpretable model-agnostic explanations (LIME) as a new visualization technique in a novel informative way to analyze the foreign direct investment (FDI) inflow. This article examines the determinants of FDI inflow through IML with a supervised learning method to analyze the foreign investment determinants in Hungary by using an opensource artificial intelligence $\mathrm{H} 2 \mathrm{O}$ platform. This author used three $M L$ algorithms-general linear model (GML), gradient boosting machine (GBM), and random forest (RF) classifier-to analyze the FDI inflow from 2001 to 2018. The result of this study shows that in all three classifiers GBM performs better to analyze FDI inflow determinants. The variable value of production in a region is the most influenced determinant to the inflow of FDI in Hungarian regions. Explanatory visualizations are presented from the analyzed dataset, which leads to their use in decision-making.
\end{abstract}

Keywords: FDI, H2O, local interpretable model-agnostic explanations, machine learning 


\section{Introduction}

Foreign direct investment (FDI) inflow has been discussed by various researchers and it reflects the importance of FDI for economic development both at the regional level and the firm level (Arel-Bundock, 2017; Gasanova et al., 2017; Singh, 2021b). The decision of foreign inverstors on where to invest is based on various parameters, which leads to differences in FDI inflow at regional levels (Makojevic et al., 2016). These wide varieties of parameters create a high dimensionality in data and to analyze these high dimensional data researchers have start using the machine-learning (ML) algorithm. Devereux and Griffith (2003) discussed the empirical literature on investment inflow through a decision tree algorithm and showed that the researchers use three types of data to analyze the FDI. Based on the data used in the research, FDI inflow investment literature can be classified into three groups: (1) discrete choice (where to locate production unit or export), (2) use of individual firm-level data (mostly examine the determinant of FDI), and (3) use of confidential data of firms.

Singh (2021b) examined FDI inflow at the regional level in Hungarian counties using an artificial neural network (ANN) and suggested that an ANN can converge a wide variety of FDI indicators - urbanization, economic, labor productivity (LP), and industrial agglomeration parametersand influence the FDI at the regional level. The RMSE value confirms that the ANN ML algorithm performs better compared to the general linear model (GLM). Schneider (2020) identified the factors affecting the dislocation decision in FDI using a large dataset of 2,361 variables from 217 countries, and employs the RF machine learning for features selection and deep neural network (DNN) to predict FDI values. The research uses the hyper-tuning of parameters to select the hidden layers in DNN and RMSE benchmarks to measure performance. The results suggest that the countries' governments should have improved the political and economic institution slowly by implementing continuous policy reforms instead of relying on a few statistically significant variables. In essence, the majority of the study discussed FDI inflow through ML models. The ML is a set of instructions that allowed the computer to predict the model but this predictability comes with a "black box" (a system that is not self-explainable and does not reveal internal mechanism). To overcome this limitation, advanced science developed interpretable machine learning (IML). IML is defined as the ability or degree to explain the behavior and predictions of the ML model which is easily understandable to humans (Molnar, 2019). Opposite of the black 
box is referred to as a "white box" (model-agonistic interpretable models). The model-agonistic method uses the black box to interpret the model and separates the explanation from the ML model. Selecting and explaining the feature through partial dependence plot (PDP) and individual conditional expectation (ICE) performed well but it has some constraints because of the limitation of one or two individual features. So, to overcome this problem, ML introduced another NextGen model-agonistic algorithm-the local interpretable model-agnostic explanations (LIME). Therefore the novelty of this article is to adapt the deep IML approach in examining the FDI inflow determinants at the regional level and proposes LIME as a visualization technique in a novel, informative way.

This research aims to determine the FDI inflow at the county level and visualize the FDI determinant through the IML algorithm. However, the specific objective of this article is categorized under two points. The first presents the IML algorithm on different high-accuracy ML classifiersgeneral linear model (GLM), gradient boosting machine (GBM) and random forest (RF) - to examine the performance in interpreting the FDI investment in counties through different performance parameters. The second developed a framework through applying ML models to find the most influencing determinant which has contributed to FDI inflow at the regional level in Hungary. This research uses both FDI inflow in regions and distribution of FDI in regions in a single research. To the best of the author's knowledge, no study has included both variables together in a single research and uses county-level data. This article attempts to fill this gap and contributes to the empirical literature. Furthermore, the present study aims to fill this literature gap by addressing the following questions: First, did the implementation of ML-based prediction system play an important role in the investment decision? Second, can the model-agonistic IML approach of LIME interpretation increase the trust level of foreign investors by creating machine-learning reports.

This article includes the following sections: (i) the literature review presents a comprehensive overview of FDI and ML interpretability; (ii) data and methodology; (iii) results and discussion, and (iv) the conclusion presents the policy implication and limitations of this research. 


\section{Literature}

The purpose of this section is to establish the platform and discuss the integration of FDI inflow and ML. The literature is presented in two parts: literature related to the integration of FDI and IML, and literature related to the integration of FDI and ML.

\subsection{Determinants of FDI and IML}

The literature on FDI and ML has widely discussed the determinants of FDI and shows the relevance at both country and regional level. The countrylevel determinants (GDP, unemployment, population, education, labor productivity, etc.) which can be a barrier or a stimulus factor for foreign firms depend on the studied region. Boudier-Bensebaa (2005) found that the Hungarian counties which have a higher agglomeration of industries, higher industrial demand, and higher labor availability attract more FDI; also, exceptionally, FDI inflow is higher in counties where the wages are higher.

Arel-Bundock (2017) investigated the influence of 31 political determinants on FDI inflow at the firm level by employing non-parametric machinelearning models and examined the prediction accuracy of adaptive boosting, extra tree, logistics, and RF regression in the scenario of FDI inflow and its political determinants. To understand politics as a driver of FDI, predictive accuracy is the best practice.

Bruneckiene et al. (2019) investigated the investment attractiveness in Europe from 2001 to 2018, using 58 economic indicators. They showed that in order to analyze the investment attractiveness, the ANN is an accurate and faster approach to handling a large number of variables more efficiently. Creativity, learning, innovativeness, intelligence, agility, and sustainability are important factors in investment attractiveness.

LIME is new concept, introduced by Ribeiro et al. (2016) as a local surrogate model. The authors tested the model for image classification with a neural network and text with $\mathrm{RF}$ regression. So, in the advancement of science, the article addresses the gap in literature that would adopt IML using the LIME algorithm to analyze the FDI inflow. 


\subsection{Determinants of FDI and ML}

Jiménez and Herrero (2019) discussed the FDI feature selection in Spain and applied the RF regression to find the features that would lead an international firm to invest in a foreign country. The results showed that the GDP growth, unemployment, and population have a minor role while product diversification plays a critical role in a firm's expansion. Pekarskiene and Susniene (2015) described the features of FDI as one of the manifestations and propulsive forces of globalization. Korgaonkar (2012) examined financial development and FDI through data mining. The research utilized the correlation-based attribute selection using a genetic algorithm and a correlation-based filter approach methodology to analyze the FDI features related to the financial sector. The results showed that FDI is not strongly diverted to financially weak countries.

Finding the FDI determinants through an ML algorithm feature selection is widely utilized because of its benefits in data visualization, reducing training time, a better understanding of data, and overcoming the high-dimensional data limitation to improve prediction performance (Guyon \& Elisseeff, 2003). The researchers mostly used RF regression to analyze the FDI predictors. Akbari et al. (2021) examined the determinant which drives economics and financial integration through ML. To overcome the multicollinearity problem, they employed the RF regression and showed that the FDI (FDI inflow, FDI outflow, and the sum of FDI inflow and outflow) improve the integration of economics and finance. Jiménez and Herrero (2019) employed the RF regression and support vector machine (SVM) to determine the features that cause the internalization of Spanish firms. Urbanization, GDP growth rate, and unemployment are significant determinants for the country-level FDI. Pratiwi (2016) analyzed and predicted the FDI in 58 countries by using data over the last 15 years in Asia, Europe, Africa, and Latin America. The performance of the model was estimated through MSE and the results showed that the $\mathrm{RF}$ with hierarchical clustering is the best model for predicting the FDI.

There are a limited number of studies that aim to determine the key contributing determinants of FDI inflow through IML. Literature shows that previous researchers implemented the high accuracy and feature selection model through the ML algorithm. Therefore, to extend this effort and contribute to the literature, there is a need to implement a novel concept of LIME to analyze the FDI determinant. 


\section{Data and methodology}

To determine the FDI inflow determinants, data was collected from Hungarian Statical Office (HCSO) across 20 Hungarian counties from 2001 to 2018. According to Lengyel et al. (2017), there is a disparity in FDI distribution in Hungary, so some regions in Hungary receive higher FDI compared to other regions. Hungarian counties can be grouped into four regions based on gross value added (GVA): reindustrialized counties, reindustrializing counties, less industrialized counties, and deindustrialized counties. So, similarly, in this research, I utilize these four groups of counties. The description of variables is given below.

Table 1. Indicators determining investment attractiveness

\begin{tabular}{|l|l|l|}
\hline Variables & Description & \\
\hline TFDI & $\begin{array}{l}\text { The total amount of FDI investment within a } \\
\text { county. }\end{array}$ & (Fazekas, 2000) \\
\hline FDIC & $\begin{array}{l}\text { Amount of FDI inflow in a county / the total } \\
\text { number FDI received companies in a county. }\end{array}$ & $\begin{array}{l}\text { (Fazekas, 2000; } \\
\text { Salike, 2016) }\end{array}$ \\
\hline Production & Value of production in counties. & $\begin{array}{l}\text { (Boudier-Bensebaa, } \\
\text { 2005) }\end{array}$ \\
\hline $\begin{array}{l}\text { Agglomera- } \\
\text { tion }\end{array}$ & $\begin{array}{l}\text { Agglomeration of industries, number of active } \\
\text { firms in counties. }\end{array}$ & $\begin{array}{l}\text { (Boudier-Bensebaa, } \\
\text { 2005) }\end{array}$ \\
\hline LP & $\begin{array}{l}\text { Total firms' revenue in a county / economically } \\
\text { active inhabitants in counties. }\end{array}$ & $\begin{array}{l}\text { (Fazekas, 2000; } \\
\text { 2005; Singh, 2021a) }\end{array}$ \\
\hline GDPPC & Gross domestic product per capita in counties. & (Schneider, 2020) \\
\hline Education & $\begin{array}{l}\text { The number of students in higher education in } \\
\text { counties. }\end{array}$ & (Fazekas, 2000) \\
\hline Urbanization & The total number of inhabitant counties. & (Patra, 2019) \\
\hline Dwelling & $\begin{array}{l}\text { Basic facilities available in households in } \\
\text { counties. }\end{array}$ & (Salike, 2016) \\
\hline Health & $\begin{array}{l}\text { Health services, number facilities available in the } \\
\text { local hospital in counties. }\end{array}$ & (Salike, 2016) \\
\hline Employment & The number of employed people in counties. & (Na \& Lightfoot, \\
2006)
\end{tabular}

Note: TFDI and FDIC are dependent variables, the article uses all variables in logscale at the regional level. 
ML is becoming popular for analyzing the data in business and economics. The ML algorithms such as RF and GBM give high accuracy but this accuracy comes with the sacrifice of explainability so this model is a black box due to its limited interpretability. This sacrifice of explainability is overcome by the IML. In this article, I used the LIME through the $\mathrm{H} 2 \mathrm{O}$ platform to analyze the FDI in Hungary.

This article utilizes the high-performance ML classifier and implements three popular black-box model algorithms: GLM, RF, and GBM. First, to find the FDI inflow determinant, I used the DPD and the ICE plot to depict the feature importance. Second, I depicted the heat plot to show the association between the variables. Third, I employed the GBM, RF, and GLM with the LIME package on open-source platform $\mathrm{H} 2 \mathrm{O}$ to find the contribution of these variables in FDI inflow. The complete practical knowledge of the $\mathrm{H} 2 \mathrm{O}$ platform is given in Cook (2017). Fourth, I compared the model's performance through different accuracy parameters. Once a model is deployed, it can used to classify, measure, and predict the model according to research objectives. I used the RStudio algorithm with LIME, vip, PDP, ggplot2, and caret library package on the $\mathrm{H} 2 \mathrm{O}$ artificial intelligence opensource platform for the identification of the most important factors determining the inflow of FDI. The following methodology was adopted in this research. The findings here are relevant in identifying the most influential and most trusted variables of FDI inflow and also provide the trusted tools for policymakers to understand the factors which influence foreign investment.

\subsection{Random forest (RF)}

Humans use the decision-making process in everyday life, in RF this decision process is called a 'decision tree'. The decision tree starts with the root node which branches further into internal nodes; this classification repeats until it reaches the leaf node (final output). The RF is composed of different decision trees to find the answer. This means that RF merges the multiple decision trees and gives the output in the form of an average of all decision trees (Gaber \& Atwal, 2013).

The decision tree can be explained by the following equations:

$$
\text { Gini }=1-\sum_{i=1}^{C}\left(p_{i}\right)^{2}
$$

Gini index is the determination of the occurrence of likely branches, where $p_{i}$ represents the relative frequency of the class you are observing in the 
dataset and $c$ represents the number of classes.

To determine how the node should branch forest through the entropy can be written as:

$$
\text { entropy }=\sum_{i=1}^{C}-p_{i} * \log _{2}\left(\mathrm{p}_{\mathrm{i}}\right)
$$

To decide which branch is a better decision for the forest, RF uses the distance of each node from the predicted actual value.

$$
M S E=1 / N \sum_{i=1}^{N}(f i-y i)^{2}
$$

Where $N$-number of data points, $f-$ value returned by the model, $y i-$ actual value at data point $i$.

\subsection{Gradient boosting machine (GBM)}

GBM is also a decision tree algorithm just like $\mathrm{RF}$ with an additional function (Cook, 2017). The formulation of GBM is according to Friedman (2001) and Natekin and Knoll (2013).

$$
(\rho t, \theta t)=\underset{\rho, \theta}{\operatorname{argmin}}\left(-\operatorname{gt}(x i)+\rho h(x i, \theta)^{2}\right.
$$

Where $\rho$-step size at $\mathrm{t}^{\text {th }}$ iteration, $-g t(x)$-boost increment in the function space, $h(x, \theta)$-base-learner function or new function parallel to the negative gradient, $i-1$ along the observed data, $\theta$-parameter estimates.

\subsection{General linear model (GLM)}

The decision tree is based on the black box and inspired by the human brain and logic, while GLM is based on mathematics. GLM uses the link function to connect the features weighted sum with the mean value of the assumed distribution. The basic mathematical expression of GLM is given as in Molnar (2019):

$$
\mathrm{g}(\mathrm{EY}(\mathrm{y} \mid \mathrm{x}))=\beta 0+\beta 1 \mathrm{x} 1+\ldots \beta_{\mathrm{p}} \mathrm{xp}
$$

Basically, the GLM consists of three components; $g$ - link function, $X^{T} \beta-$ weighted sum probability; $E_{Y}$-distribution from the exponential family. 


\subsection{Feature importance}

Along with the main model I used the PDP and ICE plot to find the feature importance of the inflow of FDI in counties and the FDI inflows in companies within a county. PDP and ICE show the nature of the features inside the model. In model-agnostic ML interpretation, PDP is a better tool to see the feature importance inside the model. The PDP for regression is defined as in Das and Tsapakis (2020) and Molnar (2019):

$$
\hat{f}_{x S}\left(x_{S}\right)=E_{x c}\left[\hat{f}\left(x_{S}, x_{C}\right)\right]=\int \hat{f}\left(x_{S}, x_{C}\right) d P\left(x_{C}\right)
$$

Where $X_{S}$-one or two features of interest and $X_{C}$-other features used in the machine-learning model $\hat{f} ; X_{S}$ and $X_{c}$ combine the whole features in the ML model.

\subsection{LIME}

Further, I needed to estimate a local model to approximate the blackbox model $f()$ around the instances of interest with the $G$ class simple interpretable model. Mathematically, the interpretability constraint can be expressed as follows:

$$
\text { explanation }(x)=\underset{\mathrm{g} \in \mathrm{G}}{\operatorname{argmin}} L\left(f, g, \pi_{x}\right)+\Omega(g)
$$

In the equation, $x$ is the model $g$ to minimize the loss function while the model complexity $\Omega(g)$ keeps low. $\pi_{x}$ defines the neighborhood size around the instances $x$.

This article uses three classifiers-GBM, RF, and GLM. All three models were built with the open-source ML platform $\mathrm{H} 2 \mathrm{O}$. The performance of the models was measured by the accuracy parameters such as RMSE and MAE, etc.

\section{Results and description}

The three classifiers used in this article-GLM, GBM and RF regressionswere built on the open-source ML platform $\mathrm{H} 2 \mathrm{O}$. Also, this article uses the PDP and ICE plots to analyze variation in the most influential feature. The PDP and ICE increase trust, accountability, and transparency by drawing the nonlinear behavior of the complex function response. The ICE is a local 
interpretability measure and PDP is a global interpretability measure but both explain any type of complex response function (Hall et al., 2019). The performance of the classifier was measured using accuracy parameters such as RMSE and MAE.

PDP plot depicts the average partial relation between one or two features and predicted response. Figure 1 shows the PDP plot for features with the highest importance variable found in RF regression feature analyses in the model, i.e., value of the production (prod) found through the feature importance plot in both cases TFDI and FDIC. The PDP plot suggests at a certain amount of value (13.5) that production has a high probability to sustain the TFDI and FDIC within a county. After the production value of 13.5, neither variable TFDI or FDIC show significant changes.

Figure 2 shows the ICE plot for the TFDI and FDIC. The ICE plot highlights the changes in fitted value throughout the range of covariates and also shows the extent of variation with heterogeneity. ICE plot is a nonlinear sensitivity analysis and depicts the functional relation between the individual feature and predicted response (Goldstein et al., 2015). Each line in the ICE plot per instance can depict the dependency of prediction on a feature compared to PDP, one line per instance in ICE is an overall prediction in PDP. It is noticeable in the PDP plot that the value of TFDI and FDIC increases around the production value of 13.5 , but it did not reveal that this is true for each dataset in TFDI and FDIC. This limitation is overcome by the ICE plot. The ICE plot in Figure 2 shows that the TFDI and FDIC have an almost similar type of variation. After comparing the TFDI and FDIC, there are some datasets in TFDI that have a high predictable probability of production greater than 1.5 while the FDIC has a maximum prediction probability of approximately 1.5 .

Figure 3 represents the heat maps and visualizes the influences of observations of each case, subsequent effect size measure is represented by the type and intensity of the color, blue color representing the positive feature weight, and pink color representing the negative feature weight. In Figure 3, the reindustrialized group has the highest weightage. For the case of FDI invested companies LP, production, industrialized group, and health are the common features that influence all five cases while in the case of FDI inflow in the counties' production and health have an association with all variables but less feature weightage. 
Figure 1. PDP plot

(a) TFDI

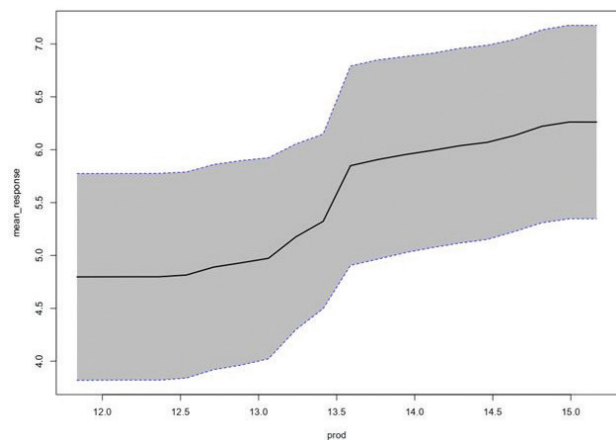

(b) FDIC

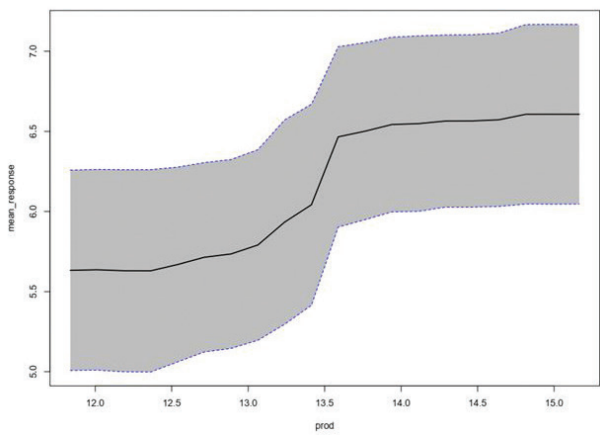

Source: Author's data.

Figure 2. ICE plot

(a) TFDI

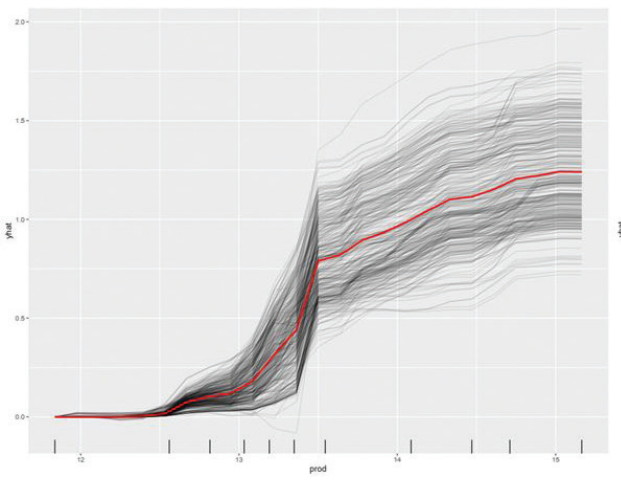

(b) FDIC

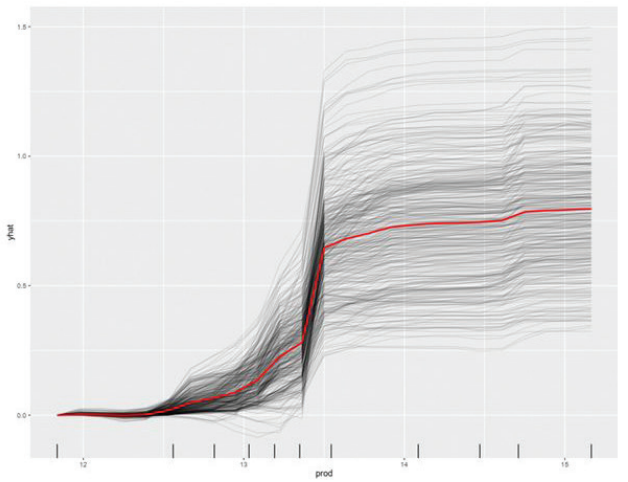

Source: Author's data.

Note: See figure in color in the online issue. Red lines in the plot present the difference in prediction compared to the prediction with the respective feature value at its observed minimum.

Explainability and interpretability are an aspect of challenges in business and economics in deep learning methods. Interpretability is the ability of the model to explain an ML output in understandable terms through a white box for both supervised and unsupervised learning. The IML can be classified into two groups-global interpretability (based on the model concept) and local interpretability (based on individual prediction). The LIME is model agnostic so it can apply in both supervised and unsupervised learning. Local interpretable explanation fits on a single variable, in this article it is the TFDI and FDIC in two different experiments that show how global model performs locally for a single observation. The process of LIME 
Figure 3. Heat map
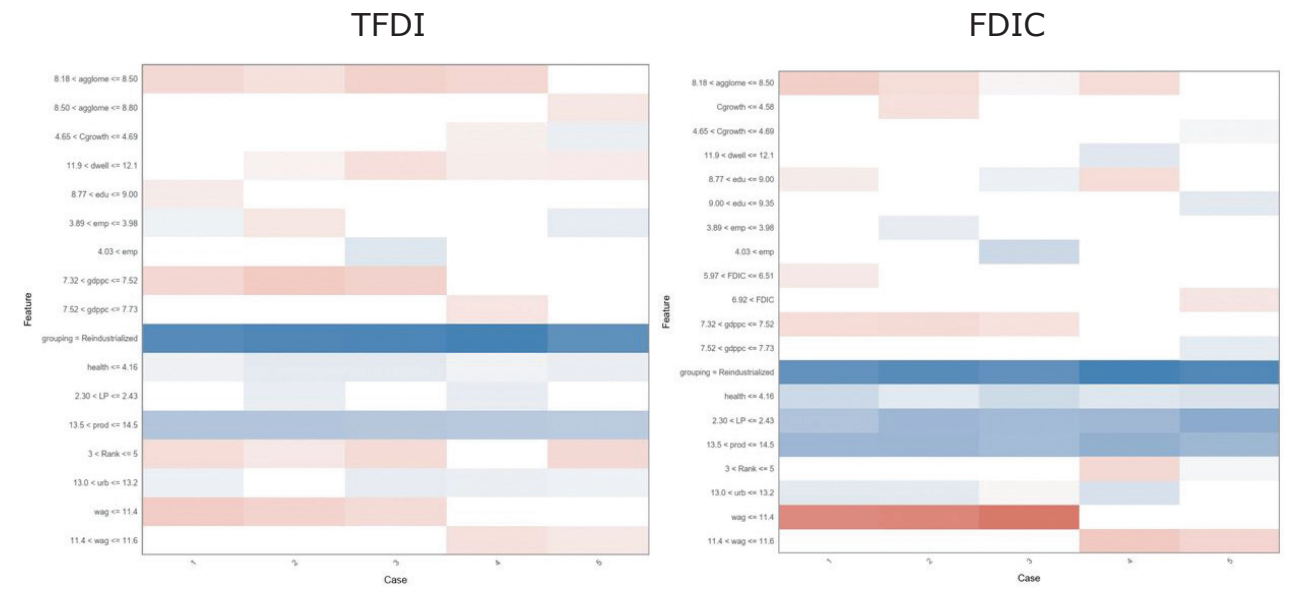

Source: Author's data.

Note: See figure in color in the online issue.

can be understood as follows: (i) permute-replication of feature data with modest value modification, (ii) similarity distance measure-measuring the distance between permuted and original observation, (iii) predict outcomes by applying the ML model, (iv) selection of features - describing the predicted outcome through selecting the number of features, (v) model fitting-fitting the model in permuted data with features and similarity scores as weight, and (vi) explanation —explaining the local behavior through features weight.

LIME algorithms classified the LIME package into two parts-object and explainer-where the object contains the feature training data. To make the model interpretable, the LIME algorithm used the explainer-object (a type of list) which contains feature distribution of training data and an ML model. After creating the objects, LIME is ready to generalize the model. By default, the feature contains 4 bins but I used 5 bins in this article. I used the following specification in LIME explainer to tune the model based on the GitHub University of Cincinnati'1: (i) I included the 5 observations (GDP per capita, the grouping of industrialization, rank of the county according to industrial agglomeration, urbanization, and labor productivity) in a local observation so, these 5 observations are approached as a new observation in order to understand why a particular predicted response was made (create a local explanation), (ii) by default the number of permutation is 5,000 for tabular data, (iii) Manhattan distance was used to compute the distance of

1 The interested reader can find the details at http://uc-r.github.io/lime. 
permuted observation, (iv) larger kernel width (instances further away also influence the model) to cover the maximum local area, and (v) the selection of features was based on the lasso regression.

Figure 4. LIME method report of the different classifiers to predict TFDI

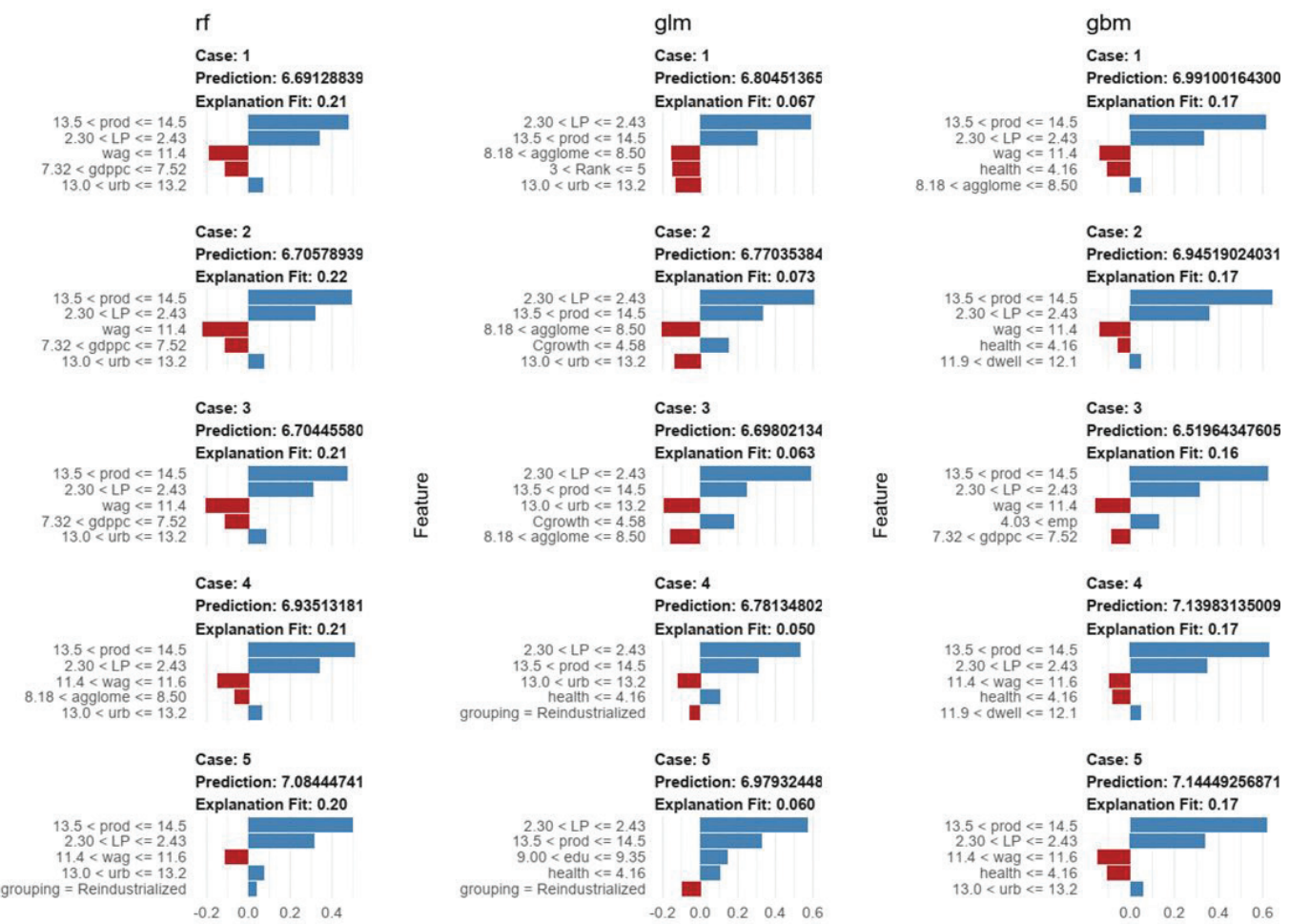

Source: Author's data. Output generated through RStudio.

Note: See figure in color in the online issue. $L P$-labor productivity, edu-education, GDPPC-GDP per capita, wages-average wages in a county, agglomeration-the number of active companies in a county, Cgrowth-the growth rate of the companies in a county, health-health services, urb-urbanization, rf-random forest, GLM-general linear model, GBM-gradient boosting machine.

The confusion matrix is not always appropriate for evaluating the model, therefore, global measures like accuracy are important but fail to explain why the model made this prediction, before implementing the model in the physical world; "trust the model" is also important like "trusting prediction". A weak trusted model can be catastrophic and a reason for a dreadful investment decision. The use of the ML and LIME is advantageous in an interpretable manner and increases the trust in the model. Five reports 
Figure 5. LIME method report of the different classifiers to predict FDIC

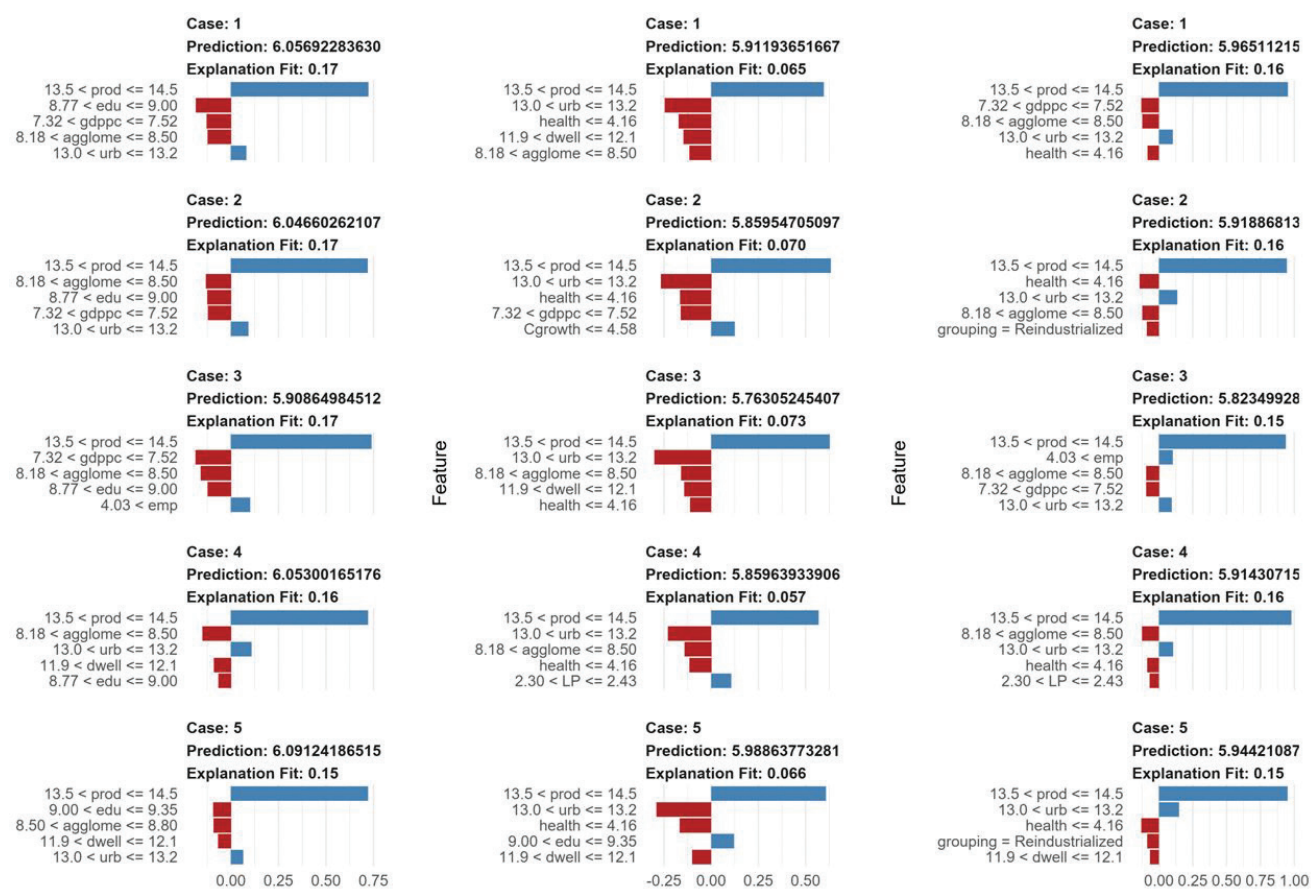

Source: Author's data. Output generated through RStudio.

Note: See figure in color in the online issue. $L P$-labor productivity, edu-education, GDPPC-GDP per capita, wages-average wages in a county, agglomeration-the number of active companies in a county, Cgrowth-the growth rate of the companies in a county, health-health services, urb-urbanization, rf-random forest, GLM-general linear model, GBM-gradient boosting machine.

for each classifier (GLM, GBM, and RF) are generated to visualize the FDI determinants of TFDI and FDIC in Figures 4 and 5, respectively. The length of the bar indicates the magnitude of the feature, while the blue color indicates the positive effect and the red color indicates the negative effect. In Figures 4 and 5, only the top five highly associated determinants are shown.

In GBM regression, three cases have an explanation fit value of 0.17 , therefore, I checked the next criteria, prediction value, to select the most suitable case. I observed that case 5 is the most preferred case which has the highest prediction value of 7.14. So, case 5 is the most suitable case for TFDI for the GBM regression. The variables production, LP, and urbanization are contributing to TFDI. Similarly, case 1 is the most suitable case for FDIC with a positive contribution to production and urbanization. In the 
$\mathrm{RF}$ regression model, case 2 is the most preferred case for TFDI and case 1 for the FDIC model. Whereas production, LP, and urbanization are, again, positively contributing variables in the case of TFDI and production and urbanization for FDIC. To explain the outcome of these variables, the works of the following researchers are referred to: Singh (2021a) suggested there is a coexistence of GDP per capita, labor productivity, and agglomeration industries in Hungary. Patra (2019) argued that there is a mutual association between FDI, economic growth, and urbanization. The term urbanization reflects the market size of the country and a region which motivates the investors to select the local region. However, the population in Hungary from 1981 is in a declining phase (Szántó, 2014). Further, Ozturk (2001) claimed that education is the fundamental factor of development and improves people's productivity and creativity, and leads the social and economic progress. Boghean and State (2015) suggest that there is a connection between FDI and labor productivity in European Union countries and this connection depends on the economic growth of the country. Overall, I observed from Figures 4 and 5 that the TFDI and FDIC decision outcome is attributed to the feature 'production', except the model GLM for TFDI which has a low explanation fit.

Table 2. Performance of RF, GBM, and GLM regression models on four performance evaluation parameters

\begin{tabular}{|l|c|c|c|c|c|c|}
\hline & RF & & GLM & & GBM & \\
\hline & TFDI & FDIC & TFDI & FDIC & TFDI & FDIC \\
\hline MSE & 0.0885621 & 0.0991081 & 0.2553673 & 0.2451834 & 0.01425472 & 0.01526311 \\
\hline RMSE & 0.2975939 & 0.3001801 & 0.5053388 & 0.4951600 & 0.11939310 & 0.12354400 \\
\hline MAE & 0.2030903 & 0.2106778 & 0.4091104 & 0.4024538 & 0.08180951 & 0.08896235 \\
\hline RMSLE & 0.0497919 & 0.0457970 & 0.0881077 & 0.0740919 & 0.02116556 & 0.01949403 \\
\hline
\end{tabular}

Source: Author's data.

Note: $M S E-$ mean square error, RMSE-root mean square error, MAE-mean absolute error, RMSLE-root mean squared log error.

Table 2 shows the performance of RF, GBM, and GLM regression models on four performance evaluation parameters. The smallest value is preferred in RMSE, MSE, MAE, and RMSLE accuracy parameters. However, RMSE is better for explaining the model accuracy because of its suitable Gaussian noise and property of being symmetry (Abdipour et al., 2019; Chuku et al., 2019; Heravi et al., 2004). After observing all four accuracy parameters in 
Table 2, GBM is performing better compared to the GLM and RF regression. Therefore, from Table 2 it is clear that the GBM is a better model compared to RF and GLM to predict the TFDI with RMSE value 0.119393 and FDIC has an RMSE value of 0.123544 .

\section{Conclusion}

This research developed an IML framework with three ML algorithms-GLM, GBM, and RF regression-to determine the best fit model for identifying the most influenced determinant for TFDI and FDIC. This article used the regional level data of Hungarian counties to present the ML interpretability of highly contributed FDI determinants through LIME in the post-socialist era throughout 2001 to 2018.

This article examines the determinants of FDI inflow through ML with supervised learning to analyze the FDI determinants in Hungary. This research intimated the practical application of IML by using an open-source artificial intelligence $\mathrm{H} 2 \mathrm{O}$ platform in the field of FDI and also depicts the PDP and ICE plot to study the features importance of FDI inflow. This study accomplished two main objectives: (i) developed a framework for applying ML models to find the most influenced determinant which contributed to FDI (TFDI and FDIC) at the regional level, and (ii) applied an IML algorithm on different high-accuracy ML classifiers (GLM, GBM, and RF) to examine the performance in interpreting the TFDI and FDIC through different performance parameters. This article shows the practical use of LIME in the field of business and economics, more specifically the FDI inflow.

Furthermore, the article also presented a literature review of previous studies that have integrated the ML, LIME interpretability and the feature selection of FDI. In addition, this study presents the methodological framework of RF, GLM, GBM, feature selection (PDF and ICE method), and LIME interpretability to analyze the FDI inflow at the regional level. The GBM outperforms in the interpretability of FDI and has shown the highest accuracy compared to other classifiers GLM and RF regression. This means that the underlying methodology can be used on the revealed and analyzed FDI through ML algorithms. The variable value of the production in a region is the most influenced determinant for the inflow of FDI in a region. The five reports generated for the TFDI and FDIC of each classifier lead to useful decision-making and foreign investments. The variables of production, LP, 
and urbanization are contributing to TFDI, however, the set of production and urbanization influence the FDIC.

The practical implications of this article are the implementation of highdimension data and information systems in the area of business and economics, where ML-based prediction systems play an important role in investment decisions. The LIME which is based on local interpretation can increase the trust level of foreign investors. This way we can find and analyze the most influenced determinant from a set of variables. Along with the merits, this study has limitations - the current study is limited to the local interpretability and identifying the TFDI and FDIC determinants, but also to the selected determinant and, thus, performing it with other variables and also in a different region is recommended.

Devesh Singh received his bachelor's degree in electronics and communication engineering from Dehradun Institute of Technology in 2010, a master's degree in business administration from the Centre for Development of Advanced Computing in 2014 and a PhD from the University of Kaposvár, Hungary in 2019. He worked at AN Square Partners as a research analyst from 2014 to 2015. His research interests include machine-learning applications in the field of economics.

\section{References}

Abdipour, M.; Younessi-Hmazekhanlu, M.; Ramazani, S. H. R. \& Omidi, A. H. (2019), 'Artificial neural networks and multiple linear regression as potential methods for modeling seed yield of safflower (Carthamus tinctorius L.),' Industrial Crops and Products, vol. 127(November 2018), pp. 185-194. https://doi.org/10.1016/j.indcrop.2018.10.050

Akbari, A.; Ng, L. \& Solnik, B. (2021), 'Drivers of economic and financial integration : a machine learning approach,' Journal of Empirical Finance, vol. 61, pp. 82-102. https://doi.org/10.1016/j.jempfin.2020.12.005

Arel-Bundock, V. (2017), 'The political determinants of foreign direct investment: a firm-level analysis,' International Interactions, vol. 43, no. 3, pp. 424-452. https://doi.org/10.1080/03050629.2016.1185011

Boghean, C. \& State, M. (2015), 'The relation between foreign direct investments (FDI) and labour productivity in the European Union countries,' Procedia Economics and Finance, vol. 32, no. 15, pp. 278-285.

https://doi.org/10.1016/s2212-5671(15)01392-1 
Boudier-Bensebaa, F. (2005), 'Agglomeration economies and location choice: Foreign direct investment in Hungary,' Economics of Transition, vol. 13, no. 4, pp. 605-628. https://doi.org/10.1111/j.0967-0750.2005.00234.x

Bruneckiene, J.; Jucevicius, R.; Zykiene, I.; Rapsikevicius, J. \& Lukauskas, M. (2019), 'Assessment of investment attractiveness in European countries by artificial neural networks: What competences are needed to make a decision on collective well-being?' Sustainability, vol. 11, no. 24, art. 6892.

https://doi.org/10.3390/su11246892

Chuku, C.; Simpasa, A. \& Oduor, J. (2019), 'Intelligent forecasting of economic growth for developing economies,' International Economics, vol. 159, pp. 74-93. https://doi.org/10.1016/j.inteco.2019.06.001

Cook, D. (2017), Practical Machine Learning with H2O:Powerful, Scalable Techniques for Deep Learning and AI, Sebastopol, CA: O’Reilly Media.

Das, S. \& Tsapakis, I. (2020), 'Interpretable machine learning approach in estimating traffic volume on low-volume roadways,' International Journal of Transportation Science and Technology, vol. 9, no. 1, pp. 76-88.

https://doi.org/10.1016/j.ijtst.2019.09.004

Devereux, M. P. \& Griffith, R. (2003), 'The impact of corporate taxation on the location of capital: A review,' Economic Analysis and Policy, vol. 33, no. 2, pp. 275-292. https://doi.org/10.1016/S0313-5926(03)50021-2

Fazekas, K. (2000), The Impact of Foreign Direct Investment Inflows on Regional Labour Market in Hungary, SOCO Project Paper, no. 77c.

Fazekas, K. (2005), 'Effects of FDI inflows on regional labour market differences in Hungary,' Économie Internationale, vol. 102 (April 2003), pp. 83-105. https://doi.org/10.3917/ecoi.102.0083

Friedman, J. (2001), 'Greedy boosting approximation: a gradient boosting machine,' The Annals of Statistics, vol. 29, no. 5, pp. 1189-1232.

https://doi.org/doi:10.1214/aos/1013203451

Gaber, M. M. \& Atwal, H. S. (2013), 'An entropy-based approach to enhancing Random Forests,' Intelligent Decision Technologies, vol. 7, no. 4, pp. 319-327. https://doi.org/10.3233/IDT-130171

Gasanova, A.; Medvedev, A. N. \& Komotskiy, E. I. (2017), 'The assessment of corruption impact on the inflow of foreign direct investment,' AIP Conference Proceedings, vol. 1836, no. 1. https://doi.org/10.1063/1.4981951

Goldstein, A.; Kapelner, A.; Bleich, J. \& Pitkin, E. (2015), 'Peeking inside the black box: visualizing statistical learning with plots of individual conditional expectation,' Journal of Computational and Graphical Statistics, vol. 24, no. 1, pp. 44-65. https://doi.org/10.1080/10618600.2014.907095

Guyon, I. \& Elisseeff, A. (2003), 'An introduction to variable and feature selection Isabelle,' Journal of Machine Learning Research, vol. 3, pp. 1157-1182. 
Hall, P.; Gill, N.; Kurka, M.; Phan, W. \& Bartz, A. (2019), Machine Learning Interpretability with H2O Driverless AI: First Edition, Mountain View, CA: H2o.ai Inc. Retrieved from http://docs.h2o.ai [accessed Mar 2021]

Heravi, S.; Osborn, D. R. \& Birchenhall, C. R. (2004), 'Linear versus neural network forecasts for European industrial production series,' International Journal of Forecasting, vol. 20, no. 3, pp. 435-446.

https://doi.org/10.1016/S0169-2070(03)00062-1

Jiménez, A. \& Herrero, Á. (2019), 'Selecting features that drive internationalization of Spanish firms,' Cybernetics and Systems, vol. 50, no. 1, pp. 25-39. https://doi.org/10.1080/01969722.2018.1558012

Korgaonkar, C. (2012), 'Analysis of the impact of financial development on foreign direct investment: a data mining approach,' Journal of Economics and Sustainable Development, vol. 3, no. 6, pp. 70-79.

Lengyel, I.; Vas, Z.; Kano, I. S. \& Lengyel, B. (2017), 'Spatial differences of reindustrialization in a post-socialist economy: manufacturing in the Hungarian counties,' European Planning Studies, vol. 25, no. 8, pp. 1416-1434.

https://doi.org/10.1080/09654313.2017.1319467

Makojevic, N.; Kostic, M. \& Puric, J. (2016), 'Može li država da utiče na regionalnu distribuciju SDI-primer Češke, Mađarske, Poljske i Srbije' [Can a state influence FDI regional distribution: the case of the Czech Republic, Hungary, Poland and Serbia], Industrija, vol. 44, no. 2, pp. 43-54.

https://doi.org/10.5937/industrija44-9590

Molnar, C. (2019), Interpretable Machine Learning. A Guide for Making Black Box Models Explainable. Retrieved from https://christophm.github.io/interpretableml-book/ [accessed Mar 2021]

Munday, M.; Roberts, A. \& Roche, N. (2009), A Review of the Economic Evidence on the Determinants and Effects of Foreign Direct Investment, Cardiff: Cardiff Business School \& Welsh Economy Research Unit.

Na, L. \& Lightfoot, W. S. (2006), 'Determinants of foreign direct investment at the regional level in China,' Journal of Technology Management in China, vol. 1, no. 3, pp. 262-278. https://doi.org/10.1108/17468770610704930

Natekin, A. \& Knoll, A. (2013), 'Gradient boosting machines, a tutorial,' Frontiers in Neurorobotics, vol. 7 (Dec). https://doi.org/10.3389/fnbot.2013.00021

Ozturk, I. (2001), 'The role of education in economic development: a theoretical perspective,' Journal of Rural Development and Administration, vol. 33, no. 1, pp. 39-47. https://doi.org/10.2139/ssrn.1137541

Patra, S. (2019), 'FDI, urbanization, and economic growth linkages in India and China,' in Socio-Economic Development: Concepts, Methodologies, Tools, and Applications, Hershey, PA: IGI Global, pp. 313-327. https://doi.org/http://doi:10.4018/978-1-5225-7311-1.ch017 
Pekarskiene, I. \& Susniene, R. (2015), 'Features of foreign direct investment in the context of globalization,' Procedia - Social and Behavioral Sciences, vol. 213, pp. 204-210. https://doi.org/10.1016/j.sbspro.2015.11.427

Pratiwi, I. (2016), Clustered Regression Models for Analysis and Prediction of Foreign Direct Investment Inflows, MA thesis in statistics and data mining, Dept. of Computer and Information Science, Linköping University.

Ribeiro, M. T.; Singh, S. \& Guestrin, C. (2016), “Why should i trust you?" Explaining the predictions of any classifier,' KDD '16: Proceedings of the 22nd ACM SIGKDD International Conference on Knowledge Discovery and Data Mining, 13-17 August, pp. 1135-1144. https://doi.org/10.1145/2939672.2939778

Salike, N. (2016), 'Role of human capital on regional distribution of FDI in China: new evidences,' China Economic Review, vol. 37, pp. 66-84. https://doi.org/10.1016/j.chieco.2015.11.013

Schneider, J. (2020), Dislocations in Foreign Direct Investment: A Machine Learning Approach to Identifying Over- and Under-Invested International Markets Schneider, Second Year Policy Analysis (SYPA), Schneider Economics.

Singh, D. (2021a), 'Cluster space among labor productivity, urbanization, and agglomeration of industries in Hungary,' Journal of the Knowledge Economy. https://doi.org/https://doi.org/10.1007/s13132-021-00726-9

Singh, D. (2021b, forthcoming), 'Comparison between artificial neural network and linear model prediction performance for FDI disparity and the growth rate of companies in Hungarian counties,' International Journal of Business Information Systems. https://doi.org/10.1504/IJBIS.2020.10034502

Szántó, I. (2014), 'Problems of a declining Hungarian birth rate: a historical perspective,' Journal of the American Hungarian Educators Association, vol. 7, pp. 95-109. https://doi.org/10.5195/ahea.2014.1 